\title{
Phospho-Tau Protein Expression in the Cell Cycle of SH-SY5Y Neuroblastoma Cells: A Morphological Study
}

\author{
Paola Flores-Rodríguez ${ }^{\mathrm{a}, \mathrm{b}}$, Charles R. Harrington ${ }^{\mathrm{c}}$, Claude M. Wischik ${ }^{\mathrm{c}}$, \\ Vanessa Ibarra-Bracamontes ${ }^{\mathrm{a}, \mathrm{b}}$, Natanael Zarco ${ }^{\mathrm{a}}$, Araceli Navarrete ${ }^{\mathrm{a}}$, \\ Alejandra Martínez-Maldonado ${ }^{\mathrm{a}, \mathrm{i}}$, Parménides Guadarrama-Ortíz ${ }^{\mathrm{d}}$, Ignacio Villanueva-Fierro ${ }^{\mathrm{e}}$, \\ Miguel Angel Ontiveros-Torres ${ }^{\mathrm{e}}$, George Perry ${ }^{\mathrm{f}}$, Alejandra D. Alonso ${ }^{\mathrm{g}}$, Benjamin Floran-Garduño ${ }^{\mathrm{a}}$, \\ José Segovia ${ }^{\mathrm{a}, *}$ and José Luna-Muñoz ${ }^{\mathrm{b}, *}$ \\ ${ }^{a}$ Deparment of Physiology, Biophysics and Neuroscience, CINVESTAV, CDMX, México \\ ${ }^{\mathrm{b}}$ Brain Bank, Laboratorio Nacional de Servicios Experimentales, LaNSE-CINVESTAV, CDMX, México \\ ${ }^{\mathrm{c}}$ School of Medicine, Medical Sciences and Nutrition, University of Aberdeen, Aberdeen, UK \\ ${ }^{\mathrm{d}}$ Depto. de Neurocirugía, Centro Especializado en Neurocirugía y Neurociencias, México (CENNM), CDMX, \\ México \\ ${ }^{\mathrm{e}}$ CIIDIR Durango, Instituto Politécnico Nacional, Becario COFAA, Durango, México \\ ${ }^{\mathrm{f}}$ School of Engineering and Science, Tecnologico de Monterrey, Toluca, México \\ ${ }^{\mathrm{g}}$ College of Sciences, University of Texas at San Antonio, TX, USA \\ ${ }^{\mathrm{h}}$ Biology Department and Center for Developmental Neuroscience, College of Staten Island, \\ The City University of New York, Staten Island, NY, USA \\ iAnahuac University North Mexico, CDMX, México
}

Handling Editor: Jesus Avila

Accepted 11 July 2019

\begin{abstract}
It has been reported that the main function of tau protein is to stabilize microtubules and promote the movement of organelles through the axon in neurons. In Alzheimer's disease, tau protein is the major constituent of the paired helical filament, and it undergoes post-translational modifications including hyperphosphorylation and truncation. Whether other functions of tau protein are involved in Alzheimer's disease is less clear. We used SH-SY5Y human neuroblastoma cells as an in vitro model to further study the functions of tau protein. We detected phosphorylated tau protein as small dense dots in the cell nucleus, which strongly colocalize with intranuclear speckle structures that were also labelled with an antibody to SC35, a protein involved in nuclear RNA splicing. We have shown further that tau protein, phosphorylated at the sites recognized by pT231, TG-3, and AD2 antibodies, is closely associated with cell division. Different functions may be characteristic of phosphorylation at specific sites. Our findings suggest that the presence of tau protein is involved in separation of sister chromatids in anaphase, and that tau protein also participates in maintaining the integrity of the DNA (pT231, prophase) and chromosomes during cell division (TG-3).
\end{abstract}

Keywords: Alzheimer's disease, cell cycle, phospho-tau protein, SC35, SH-SY5Y, staurosporine

*Correspondence to: José Luna-Muñoz, Brain Bank, Laboratorio Nacional de Servicios Experimentales, LaNSE-CINVESTAV, CDMX, México. E-mail: jluna@ cinvestav.mx and José Segovia,
Department of Physiology, Biophysics and Neuroscience, CINVESTAV, CDMX, México. Tel.: +52 57473800; Ext: 1748; Fax: +52 57473800; Ext 5713; E-mail: jsegovia@ fisio.cinvestav.mx. 


\section{INTRODUCTION}

Microtubules, which are a major component of the cytoskeleton, are dynamic structures that undergo continual assembly and disassembly within the cell $[1,2]$, determine cell shape, and function of the intracellular transport of organelles and separation of chromosomes during cell division [2], and are composed of $\alpha$ - and $\beta$-tubulin dimers [3] and their assembly and stability involves microtubuleassociated proteins (MAPs). The best characterized of these are MAP1, MAP2, and tau protein [4]. In human brain tissue, six tau isoforms (342-441 amino acids in length) are expressed and these are generated by alternative splicing of exons 2, 3, and 10 . Exons 2 and 3 encode two $\mathrm{N}$-terminal inserts, whereas exon 10 encodes an additional tandem repeat within the C-terminal domain that gives rise to 3- and 4repeat isoforms ( $3 \mathrm{R}$ and $4 \mathrm{R}$ ) $[5,6]$. Tau protein has been extensively studied since it was identified as the major component of the neurofibrillary tangles (NFTs) isolated from brains of Alzheimer's disease (AD) patients [6]. NFTs are formed by the accumulation of abnormal tau and, under electron microscopy, appear as paired helical filaments [7, 8]. Tau protein can be hyperphosphorylated and truncated, postranslational events that would favor the generation of a series of conformational misfoldings. Tau protein is an abundant protein having a diverse cellular distribution and is likely to have multiple functions; this protein, found in the plasma membrane, is dephosphorylated at serine/threonine residues, suggesting that the phosphorylation state of tau regulates its intracellular trafficking. Dephosphorylation of tau may increase the association of tau with trafficking proteins which target tau to the plasma membrane [9]. Other studies have shown the presence of tau protein in the nucleus of both neuronal and nonneuronal cells [10-12]. Tau protein, expressed in the nucleolus of mitotic HeLa cells, is involved in nucleolar organization [13]. It has also been found in the nucleolus of undifferentiated human neuroblastoma cells SH-SY5Y, and it has been suggested that nuclear tau could participate in the synthesis, assembly, and transport of ribosomes [14-16]. Whereas the $3 \mathrm{R}$ tau isoform is expressed in undifferentiated SH-SY5Y cells, both $3 \mathrm{R}$ and $4 \mathrm{R}$ isoforms are expressed following differentiation of these cells [17]. The splicing factor SC35, a member of the superfamily of the serine/arginine-rich (SR) protein, promotes inclusion of the tau exon 10. Nuclear speckles, as granular clusters, are nuclear domains enriched in pre-mRNA splicing factors, located in the interchromatin regions of nucleoplasm [18].

The aim of this study was to analyze the pattern of expression and cellular localization of phospho-tau protein during cell cycle division and its relationship with SC35 (speckles) in both cultured neuroblastoma cells and AD brain.

\section{MATERIALS AND METHODS}

\section{Brain tissue}

Brain tissues from six $\mathrm{AD}$ patients were examined in this study (ages 47-90 years, mean 67.5 years, with 2-6 hour postmortem delay). These were obtained from the National Brain Bank CINVESTAV, Mexico. Autopsies were performed on donors from whom written informed consent had been obtained either from the donor or direct next of kin. The diagnosis of AD was obtained by the NIA-NINCDS group criteria [19]. Blocks of the hippocampus and adjacent entorhinal cortex were fixed by immersion in a solution of $4 \%$ paraformaldehyde in phosphate-buffered

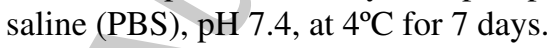

\section{Cell culture}

The human neuroblastoma SH-SY5Y cell line (ATCC, Manassas USA), was maintained in DMEM high glucose (Gibco, USA) supplemented with $10 \%$ heat-inactivated fetal bovine serum (FBS), l-glutamine $(2 \mathrm{mM})$, penicillin $(100 \mathrm{U} / \mathrm{ml})$, and streptomycin $(100 \mu \mathrm{g} / \mathrm{ml})$ under an atmosphere of $5 \%$ $\mathrm{CO}_{2}$, in a humidified incubator at $37^{\circ} \mathrm{C}$.

For immunofluorescence, cells were seeded at $2.5 \times 10^{4}$ cells on $12 \mathrm{~mm}$ glass coverslips. Coverslips were maintained in 4-well dishes (Falcon $1.39 \mathrm{~cm}^{2}$ ), in DMEM high glucose supplemented with $10 \%$ FBS, glutamine and antibiotics in a $5 \% \mathrm{CO}^{2}$ incubator at $37^{\circ} \mathrm{C}$ for $48 \mathrm{~h}$. To induce differentiation, $70 \%$ confluent cultures were treated for seven days with retinoic acid $(10 \mu \mathrm{M})$, in DMEM high glucose supplemented with $1 \%$ FBS. Treatment with staurosporine (Sigma, St. Louis Mo. USA) was at a concentration of $0.02 \mu \mathrm{M}$ for $12 \mathrm{~h}$.

\section{Isolation of nuclear fraction}

The procedure described by Guillemin et al. was used to isolate the nuclear fraction from SH-SY5Y 
cells [20]. Briefly, monolayer cultures grown in 100$\mathrm{mm}$ petri dishes were harvested by trypsination and washed once with PBS. From here on, all the steps were done at $4{ }^{\circ} \mathrm{C}$ and the buffers supplemented with protease and phosphatase inhibitor cocktails (Sigma, USA). The pellet was resuspended in CLB buffer (10 mM HEPES, $10 \mathrm{mM} \mathrm{NaCl}, 1 \mathrm{mM} \mathrm{KH}_{2} \mathrm{PO}_{4}$, $5 \mathrm{mM} \mathrm{NaHCO} 3,5 \mathrm{mM}$ EDTA-Na, $1 \mathrm{mM} \mathrm{CaCl}$, $0.5 \mathrm{mM} \mathrm{MgCl}_{2}$ ) to a ratio of $7-8 \times 10^{6}$ cells $/ 0.5 \mathrm{ml}$ and then incubated for $5 \mathrm{~min}$ on ice. The homogenization was performed by applying 20-30 passages through a 22-gauge needle, then isotonicity of this crude homogenate was restored by adding $50 \mu$ l of $2.5 \mathrm{M}$ sucrose (a small aliquot of this extract was kept at $-20^{\circ} \mathrm{C}$ for further analysis) before centrifugation at 6300xg in a tabletop centrifuge (Beckman, USA). The pellet was resuspended in $1 \mathrm{ml}$ TSE buffer (10 mM Tris, $300 \mathrm{mM}$ sucrose, $1 \mathrm{mM}$ EDTA$\mathrm{Na}_{2}, 0.1 \%$ NP-40) and homogenized by 20 passages through a 22-gauge needle. The suspension was centrifuged at 4000xg for $5 \mathrm{~min}$, the supernatant stored at $-20^{\circ} \mathrm{C}$ as source of cytoplasm extract, and the pellet washed with TSE buffer until the supernatant was completely clear. The pellet was resuspended in $100 \mu \mathrm{l}$ TSE buffer (nuclei) and stored at $-20^{\circ} \mathrm{C}$ until used. The protein content of the fractions was determined using BCA protein assay (Thermo Fisher Scientific, USA).
Immunoblotting

Protein samples $(40-50 \mu \mathrm{g})$ were separated by 10-12\% SDS-PAGE, transferred onto PVDF membrane (Bio-Rad, USA) and probed using antibodies to ascertain the purity of the different fractions. Antihuman GAPDH antibody was used as a control for the cytoplasmic fraction and anti-human lamin A/C for nuclear fraction. The detection was visualized after applying specific secondary HRP-conjugated antibodies and exposure to ECL chemiluminescent substrate (Perkin Elmer, USA)

\section{Antibodies}

General characteristics of the antibodies used are summarized in Table 1.

\section{Immunofluorescence}

\section{Double immunolabeling in AD brain tissue}

Free-floating sliding microtome sections $(50 \mu \mathrm{m})$ were treated with Pronase $(0.5 \%)$ for $20 \mathrm{~min}$ and formic acid pure for $1 \mathrm{~min}$ before the immunolabeling. After, sections were blocked with a $0.2 \%$ IgG-free albumin solution (Sigma Aldrich.) in PBS for $20 \mathrm{~min}$ at room temperature. Sections were then incubated with primary antibodies cocktail pSer404

Table 1

Antibodies and recognition sites

\begin{tabular}{llll}
\hline Antibody & Epitope (amino acid residue numbers) & $\begin{array}{l}\text { Species and } \\
\text { isotype }\end{array}$ & Reference, source \\
\hline Alz-50 & Tau 5-15, 312-322. Structural conformational change & Mo IgM & {$[21,22]$} \\
TG-3 & Tau phospho-Thr231. Regional conformational change & Mo IgM & [23] \\
pT231 & Tau phospho-Thr231 & Rb IgG & Thermo Fisher \\
pT235 & Tau phospho-Ser235 & Rb IgG & {$[24]$, Abcam } \\
AT100 & Tau phospho-Ser202, Thr205, Thr212, Ser214. Regional & Mo IgG & [25], Thermo Fisher \\
& conformational change & Mo IgG & [26] \\
AD2 & Tau phospho-Ser396, Ser404 & Rb IgG & Thermo Fisher \\
pSer396 & Tau phospho-Ser396 & Rb IgG & [27], Thermo Fisher \\
pSer400 & Tau phospho-Ser400 & Rb IgG & Thermo Fisher \\
pSer404 & Tau phospho-Ser404 & Rb IgG & Thermo Fisher \\
pSer422 & Tau phospho-Ser422 & Rb IgG & [28], Thermo Fisher \\
Tubulin & Alpha-tubulin & Mo IgG & [29] \\
Tau-5 & Mid-tau 210-241 & Mo IgG & [30] \\
Tau-1 & Tau dephosphorylated 195,198, 199 and 202 & Mo IgG & [31] \\
Tau-7 & Tau C-terminus & Mo IgG & [32] \\
T46 & Tau 404-441 & Mo IgG & [33] \\
Tau499 & Tau N-terminus 14-26 & Mo IgG & [34], Sigma Aldrich \\
SC35 & Recognizes a phospho-epitope of non-snRNP (small nuclear & & Rb IgG \\
GAPDH & ribonucleoprotein particles) & Rb IgG & [35], Millipore \\
Lamin A/C & Glyceraldehyde 3-phosphate dehydrogenase & Lamin A/C & Abcam \\
\hline
\end{tabular}

Mo, mouse; Rb, rabbit; IgG, immunoglobulin G; IgM, immunoglobulin M Fluorescent dyes: Rhodamine phalloidin (Sigma-Aldrich), TO-PRO-3-iodide (Molecular Probes) were used to visualize actin filaments and nuclei, respectively. 
(1:100 dilution) and $\mathrm{T} 46(1: 100)$ overnight at $4^{\circ} \mathrm{C}$, and then with FITC-tagged goat-anti-rabbit IgG CY5tagged goat anti-mouse IgG secondary antibodies (Jackson Immunoresearch Lab Inc., West Grove). PBS-0.2\% Triton X-100 (Sigma Aldrich) solution was used in all of the immunolabeling steps. Samples were counterstained with the dye Thiazin red (TR) to differentiate non-fibrillar from fibrillar states of tau aggregates [36].

\section{Double and triple tau protein immunolabeling in SH-SY5Y cells}

Cells were fixed with $4 \%$ paraformaldehyde in PBS (pH7.4) for $30 \mathrm{~min}$ at room temperature, followed by permeabilization in $0.2 \%$ triton-X100 for $10 \mathrm{~min}$ (Sigma Aldrich) in PBS and then blocked with 0.2\% IgG-free albumin solution (Sigma Aldrich) in PBS for $20 \mathrm{~min}$ at room temperature, incubated at $4^{\circ} \mathrm{C}$ overnight with the primary antibodies (see Table 1) and revealed using a mixture of secondary antibodies specific for species and immunoglobulin isotype used. Samples were counterstained with $0.0001 \%$ To-Pro-3 iodide dye (InVitrogen) in PBS. For triple labelling, cells were incubated with a primary antibody cocktail consisting of pT231, pS235, pS396, or TG-3 with tubulin at $4{ }^{\circ} \mathrm{C}$ overnight and counterstained with To-Pro-3 iodide dye.

For the detection of the intranuclear speckle structures, we used a monoclonal antibody raised against the splicing factor SC35 (Sigma Aldrich) diluted 1:100. Anti-SC35 and pT231 antibodies were applied simultaneously (1:200) and counterstained with To-Pro-3 iodide dye in differentiated and undifferentiated SH-SY5Y cells.

\section{Confocal microscopy}

Double and triple immunolabeled sections were mounted in anti-quenching media Vectashield (Vector Labs, Burlingame) and viewed through a confocal laser scanning microscope (TCP-SP8, Leica, Heidelberg) using a $20 \mathrm{X}$ dry and 100X oil-immersion plan Apochromatic objectives (NA 1.4). Ten to fifteen consecutive single sections were obtained at $0.8-1.0 \mu \mathrm{m}$ intervals and sequentially scanned in all channels throughout the $\mathrm{z}$-axis of the sample. The resulting stack of images was projected and analyzed onto the two-dimensional plane using a pseudocolor display green (FITC), red (TRITC), and blue (CY5). Fluorochromes in double and triple labeled samples were excited at $488 \mathrm{~nm}$ (for FITC), $540 \mathrm{~nm}$ (for TRITC), and $650 \mathrm{~nm}$ (for CY5). The autofluorescence of lipofuscin granules in $\mathrm{AD}$ brain tissue was observed in the red channel. The images were analyzed using Leica SP8 software.

\section{Immunoelectronmicroscopy}

Brain blocks from AD hippocampus were fixed by immersion in a mixture of $4 \%$ paraformaldehyde and $0.2 \%$ glutaraldehyde in PBS (pH 7.3) at $40^{\circ} \mathrm{C}$ for $2.5 \mathrm{~h}$ after post-fixation with a $1 \%$ osmium tetroxide solution for one additional hour, tissue was embedded in lowicryl resin and polymerization was performed under ultraviolet light for $72 \mathrm{~h}$. Ultrathin sections were put on nickel grids and then processed for gold-immunolabeling as follows: incubation with Alz50 (1:20 dilution in PBS) for $45 \mathrm{~min}$ at room temperature; 2) incubation with an anti-mouse gold-conjugated-IgM secondary antibody (Amersham, UK) (20 nm particle diameter) diluted at 1:100. As a control for antibody specificity some sections were incubated with the non-ADrelated primary antibody, CB-Help1, and similarly processed. Immunolabeled ultrathin section were counterstained with uranyl salts and viewed using an electron microscope (JEOL, JEEM 2000EX).

\section{RESULTS}

Expression of tau protein in nucleus

Subcellular fractionation of neuroblastoma cells

Despite the abundance of axonal tau in neural tissue in humans without neurological alterations and in wild-type mice, the protein is difficult to visualize. To demonstrate the presence of nuclear tau, therefore, we separated the nuclear fraction to show the presence of intact, phosphorylated tau protein in the nucleus.

SH-SY5Y neuroblastoma cells were analyzed by immunoblots. These include undifferentiated (Fig. 1A-C, E, F) and differentiated cells (Fig. 1D) separated by SDS-PAGE as total homogenate (lane 1 ), cytosol (lane 2), and nuclear fraction (lane 3). The extent of purification was established by the presence of two bands recognized by lamin $\mathrm{A} / \mathrm{C}$ at 60-75 kDa in the nuclear but not the cytoplasmic fraction (Fig. 1E). Conversely, the 38-kDa GAPDH was observed only in the cytoplasmic fraction (Fig. 1F, Lane 3). 

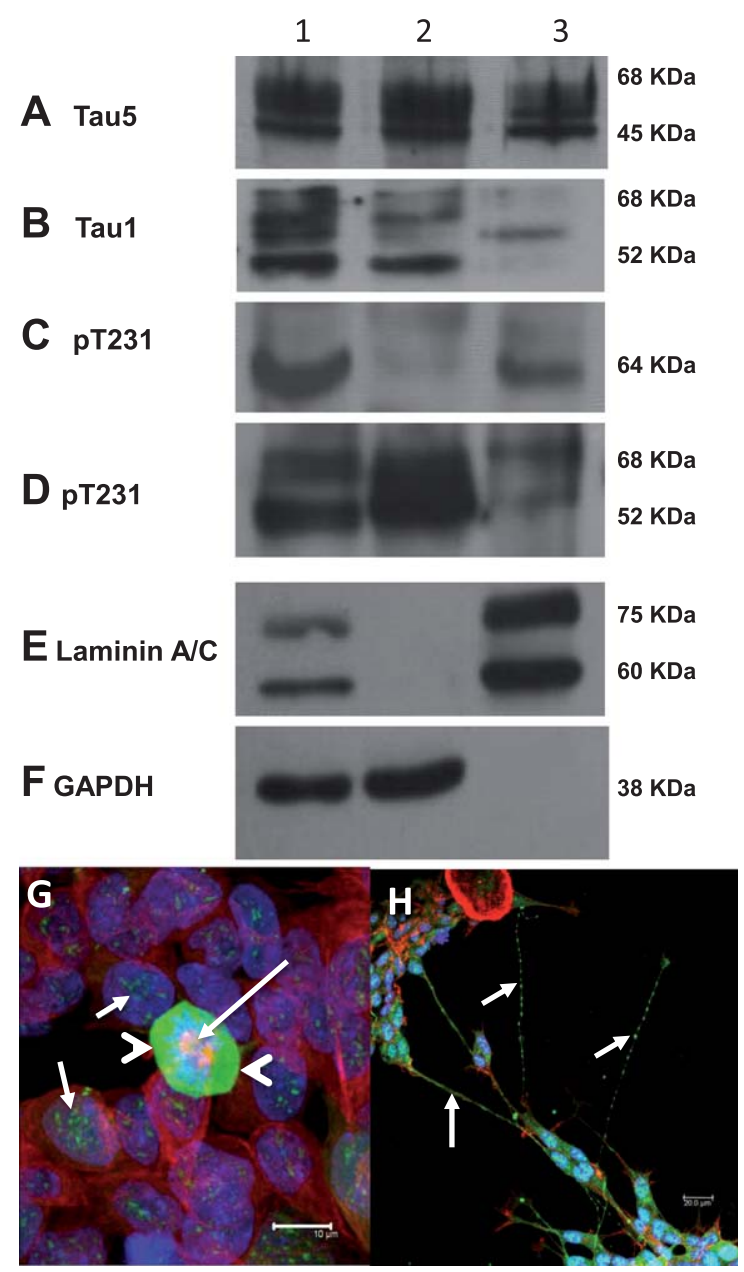
C, E-F), obtained from total cell homogenate (lane 1), cytosolic fraction (lane 2), and nuclear fraction (lane 3) with the antibodies indicated. Relative molecular mass for immunoreactive bands is given on right. Figures show representative figures from three independent experiments. In the panel below $(\mathrm{G}, \mathrm{H})$, double immunostaining of cells in culture shows dense spots in the nucleus (small arrows) labeled with pT231 antibody (green channel) surrounded by tubulin and actin networks (red channel) and within the nucleus counterstained with TO-PRO (blue channel). A cell undergoing division (arrowheads) shows the mitotic spindle stained strongly for tubulin (G, large arrow) in undifferentiated cells. For differentiated cells, the immunoreactivity of the pT231 antibody is observed abundantly in the cell nucleus and staining in the form of a string of beads is observed along the cytoplasmic extension (H, arrows).

\section{Expression of tau protein in undifferentiated} SH-SY5Y cells

Tau-5 (Fig. 1A), an antibody that recognizes an epitope in residues $210-241$ of tau protein, reacts with two dense bands of $45-68 \mathrm{kDa}$, in the total
Fig. 1. Immunoblots from undifferentiated SH-SY5Y cells (Ahomogenate, and in the cytoplasmic and nuclear fractions. Tau-1, an antibody that depends upon the dephosphorylation of tau on residues 195-202 (Fig. 1B), reacts with 4 bands of $52-68 \mathrm{kDa}$ in the total homogenate (lane 1). After fractionation, three of these bands were found in the cytoplasmic fraction (lane 2), and a single band of $64 \mathrm{kDa}$ in the nuclear fraction (lane 3). The antibody directed against the phosphorylated tau epitope at amino acid Thr-231 (pT231, Fig. 1C) recognized a dense band in total homogenate (lane 1) and nuclear extract (lane 3), having an approximate weight of $64 \mathrm{kDa}$, that was not present in the cytoplasmic fraction (lane2).

Expression of phosphorylated tau protein in differentiated human SH-SY5Y cells

The pT231 antibody reacted with two bands of 52 and $68 \mathrm{kDa}$ in total homogenate that were present in both cytoplasmic and nuclear fractions (Fig. 1D).

Expression of the tau protein phosphorylated at Thr-231 is associated with the cell cycle changes

pT231 immunoreactivity in undifferentiated cells was seen in thick and dense spots, or speckles, in the nucleus of quiescent cells (Fig. $1 \mathrm{G}$, small arrows). In addition, a fine granular staining was observed in the cytoplasm. This immunoreactivity increases throughout the cytoplasm as cells enter the division cycle (Fig. $1 \mathrm{G}$, arrowheads), where the mitotic spindle and microtubules of the cytoskeleton are visualized with tubulin antibody (Fig. $1 \mathrm{G}$, long arrow). When cells are differentiated with retinoic acid (Fig. $1 \mathrm{H}$ ), long cytoplasmic extensions form at the end where the growth cone was detected, and where the expression of pT231 was observed like a string of beads. The cytoskeleton of these cells was revealed with rhodamine-conjugated phalloidin (red channel). Additionally, a granular immunoreactive staining pattern was observed in the nucleus of differentiated cells with this antibody.

Double immunolabelling with the pT231 and TG-3 antibodies with undifferentiated $S H-S Y 5 Y$ cells

The immunoreactivity of the pT231 antibody was associated with intranuclear specks in quiescent cells (Fig. 2A, arrowheads, green channel). As the cells enter the cell cycle, there was an increase of pT231 immunoreactivity (Fig. 2A, arrows, red channel). 
However, the labeling of the TG-3 antibody was only observed in cells undergoing cell division (Fig. 2A, arrows, red channel). TG-3 immunoreactivity was concentrated in the periphery of the chromosomes as revealed by To-PRO (2A-C, blue channel). In cells undergoing cytokinesis, pT231 immunoreactivity decreases drastically (Fig. 2B, arrows) and dense granular staining is observed in the cytoplasm associated with nuclei, in cells in the cytokinesis process the TG-3 antibody showed no reactivity (Fig. 2B, arrows). Magnification (2A') of the image 2A, where a single optical image is shown, the immunoreactivity of the TG-3 antibody (2A', arrowheads, red channel) is more intense in the periphery of the chromosomes.
However, the immunoreactivity of the pT231 antibody was observed homogenously throughout the cytoplasm ( $2 \mathrm{~A}^{\prime}$, green channel)

Double immunolabelling with antibodies pT231 and $A T 100$

The immunoreactivity with the AT100 antibody was characterized as dense granular speckles in quiescent cells (Fig. 2 C, arrowheads, red channel) and these colocalized with pT231 reactivity (Fig. 2C, merged image) AT100 immunoreactivity did not increase during cell division (Fig. 2C, arrows).
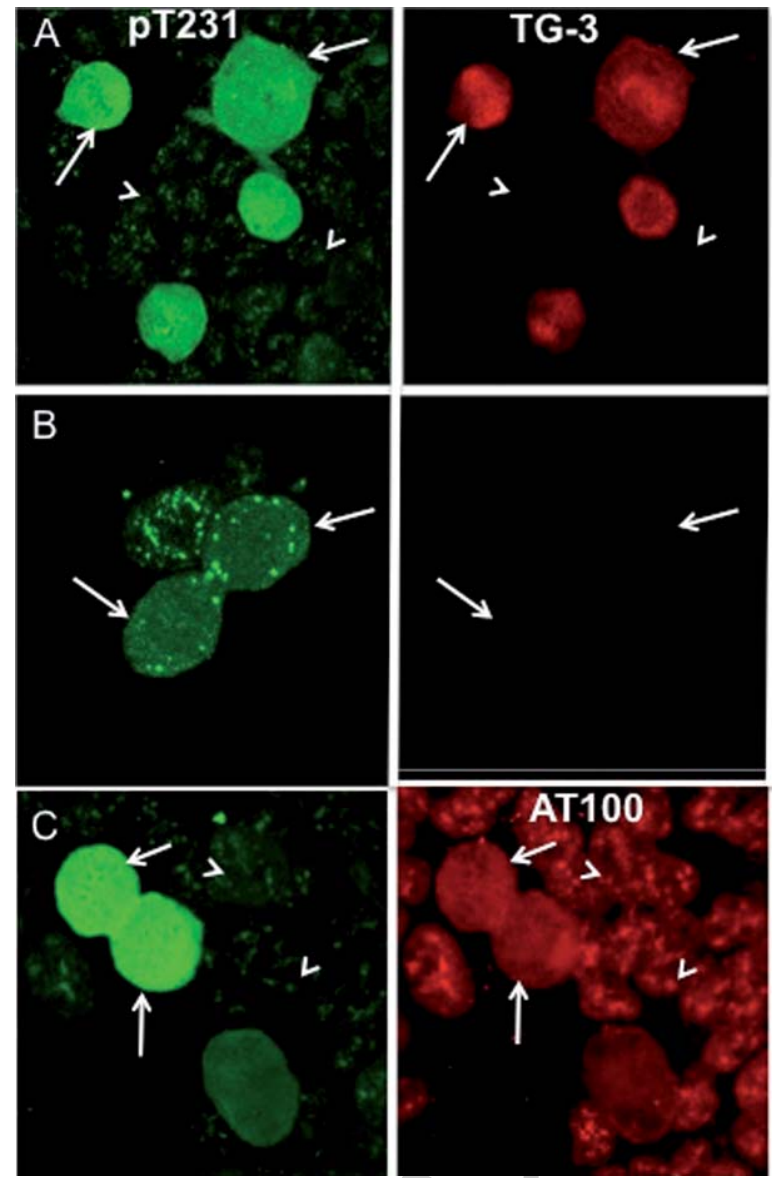
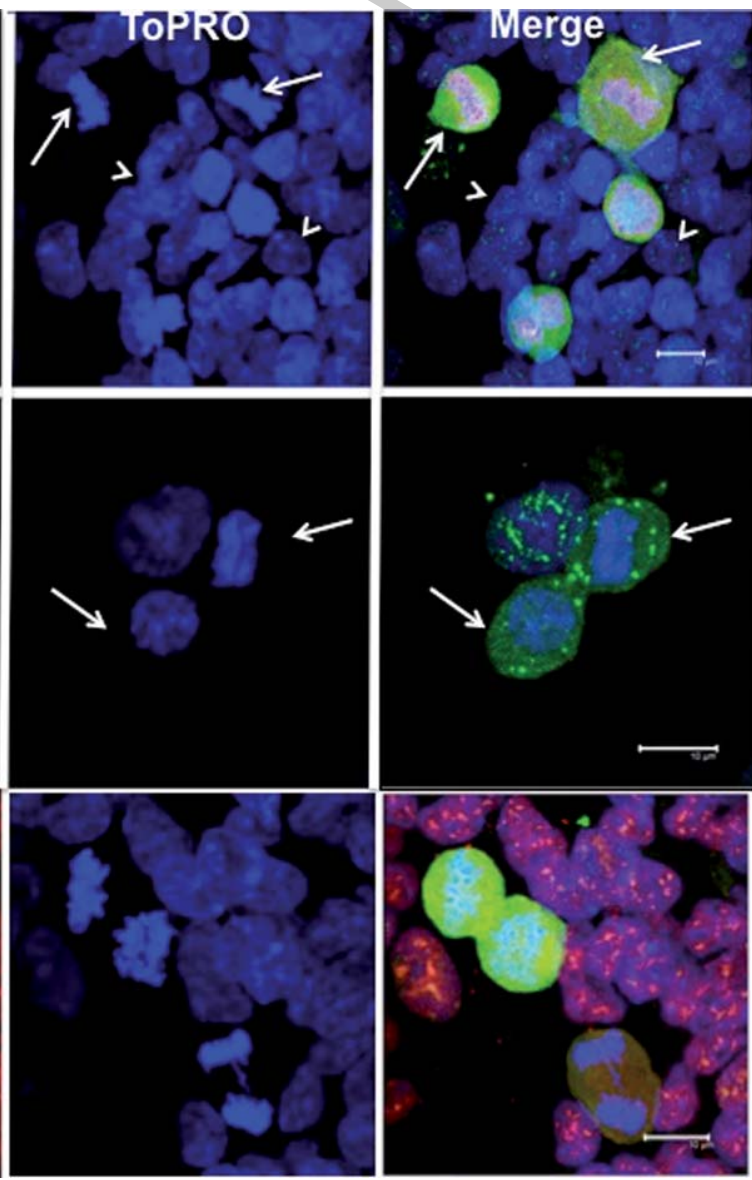

Fig. 2. Double immunostaining of undifferentiated SH-SY5Y cells with antibodies directed against phosphorylated epitopes in tau protein (pT231, green channel and TG-3 or AT100, red channel) and contrasted with To-PRO dye (blue channel). A) In quiescent cells the dye is located in dense granules that are immunoreactive for pT231 (arrowheads). Immunoreactivity for both pT231 and TG-3 increases in cells undergoing cell cycle (merged image). A') Magnification of image A, where a single optical image shown on the middle body cell. TG-3 immunoreactivity bordering the chromosomes. B) By the end of cell cycle, immunoreactivity for the pT231 antibody decreases (arrows, green channel) and, in the periphery, dense spots are observed, while immunoreactivity for TG-3 disappears (red channel). C) Immunoreactivity for AT100 does not differ in intensity between quiescent cells (arrowheads) and dividing cells (arrows). 
Immunoreactivity pattern of the AD2 antibody in undifferentiated $\mathrm{SH}$-SY5Y cells

The affinity of the AD2 antibody depends on the phosphorylation of amino acids serine 396 and serine 404. The staining pattern of this antibody was characterized by fine granular staining in the nucleus of quiescent cells (Fig. 3A, small arrows). However, the immunoreactivity of this antibody increased in cells entering cell division (Fig. 3A, large arrow). At anaphase, AD2 immunoreactivity increased in the middle of the cluster of chromosomes migrating toward their poles (Fig. 3B).

\section{Double immunostaining with pT231 and anti-tubulin antibodies}

Undifferentiated SHSY-5Y cells were immunostained with both pT231 (green channel) and tubulin (red channel) antibodies (Fig. 4). The immunoreactivity of pT231, was observed in quiescent (post-mitotic) cells as an intranuclear granular staining pattern (speckles) (Fig 4A, arrows), immunoreactivity to the anti-tubulin antibody clearly shows the cytoskeletal fibers of the cytoplasm. pT231 immunoreactivity increases in the nucleus, where the reactivity is characterized by abundant diffuse granular staining in the nucleus (Fig. 4B, short arrows). Condensation of the chromosomes is evident at this stage; the immunoreactivity of the anti-tubulin antibody increases at two dense points at opposite poles to the periphery of the nucleus. The cell is completely round and the immunoreactivity of the pT231 antibody increases considerably in intensity in the cytoplasm and in the microtubular kinetochore (mitotic spindle) is formed (Fig. 4C). Immunoreactivity to pT231 decreases as sister chromatids migrate toward the opposite poles of the cell, at which stage there is scarce granular staining. However, immunoreactivity to pT231 is still observed in the cytosol (Fig. 4D). Finally, when chromosomes are concentrated at each of the poles at the initiation of cytokinesis, diffuse granular pT231 immunoreactivity is scarce. The microtubules become fragmented on preparing for the separation of the sister cells (Fig. 4E).

Double immunostaining with SC35 and pT231 antibodies

The SC35 antibody demonstrates the intranuclear structures called speckles, which are pre-mRNA
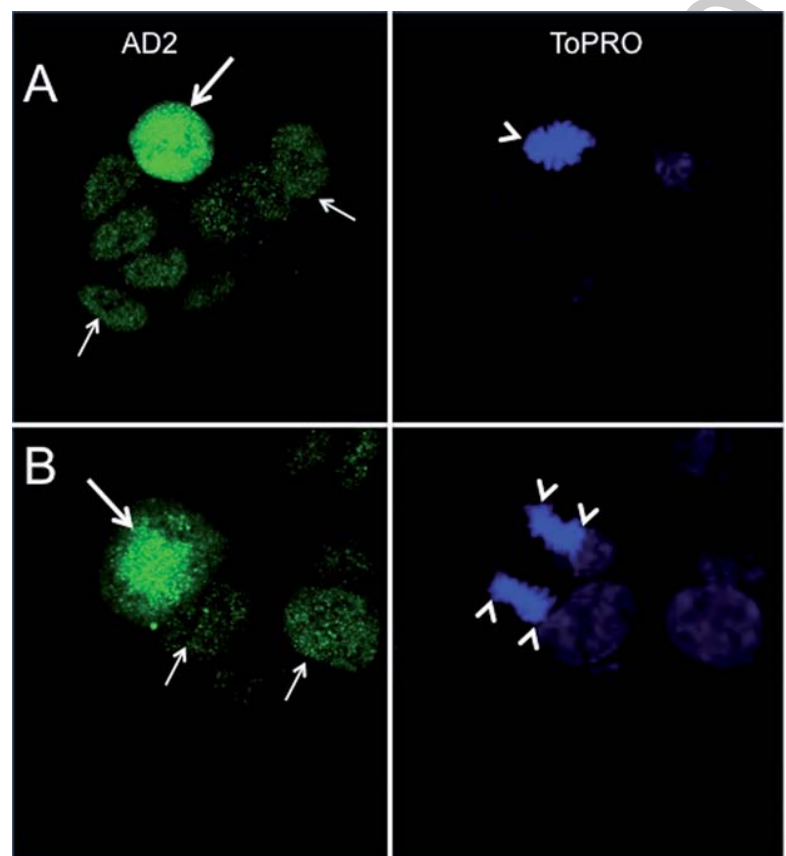

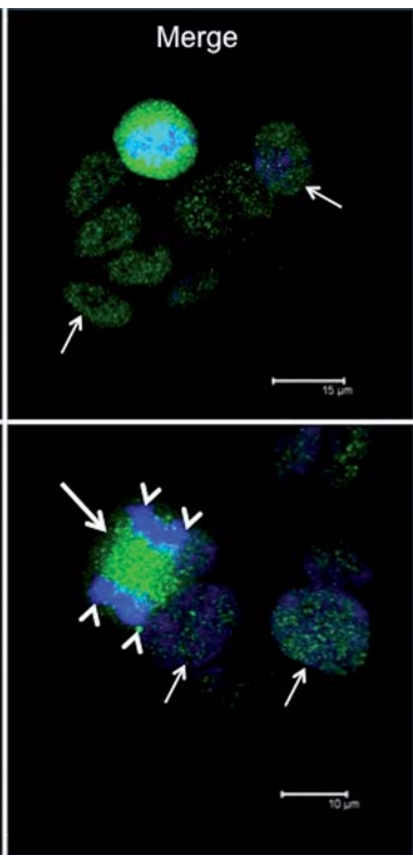

Fig. 3. Immunolabelling with AD2 (green channel) counterstained with TO-PRO dye. A) Immunoreactivity of the AD2 antibody increases in cells cycle (large arrow), whereas in quiescent cells there is a fine granular stain in the nucleus (small arrows). B) The affinity for the AD2 antibody is increased (large arrow) between sister chromatids (arrowheads). 


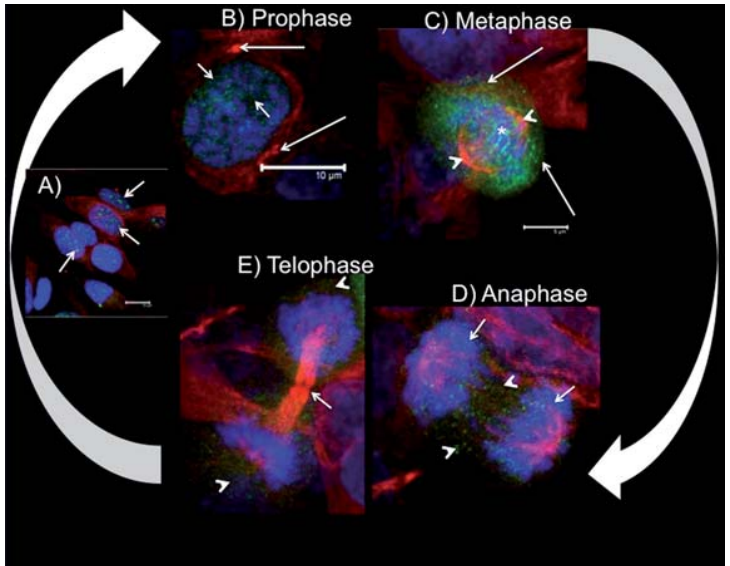

Fig. 4. Double immunostaining with antibodies pT231 (green channel) and tubulin (red channel), counterstained with the TOPRO dye (blue channel). A) pT231 tau is seen in dense spots in quiescent cells within the nucleus. B) During prophase, condensation of the chromosomes is observed, and phospho-tau immunoreactivity is increased in a diffuse granular staining pattern (small arrows) with centrioles seen with tubulin antibody (large arrow). C) During metaphase, the spindle has developed (arrowheads) and chromosomes are found in the equator (asterisk). At this stage, pT231 immunoreactivity fills the entire cellular cytoplasm. D) In anaphase, the sister chromatids have separated and lie towards the poles (arrows), whereas pT231 immunoreactivity decreases to a diffuse granular staining. E) During telophase, in cytokinesis and nucleation, pT231 immunoreactivity decreases drastically (arrowheads).

splicing intranuclear domains found in the interchromatin regions of the cell nucleoplasm. In SH-SY5Y cells, the SC35 antibody revealed dense speckles in the nucleus of quiescent cells (Fig 5A, green channel, arrowhead), which colocalize with pT231 immunoreactivity (Fig 5A, red channel and merged, arrowhead). However, some granules reactive to pT231 were not recognized by anti SC35. During prophase, the nuclear speckles undergo a redistribution into dense granules immunoreactive to SC35 (Fig. 5B). These dense granules colocalize with the expression of tau protein, in the nucleus, and a diffuse staining was observed in the nucleoplasm (Fig. 5B, arrow, green channel). Speckles are commonly observed at the periphery of nuclei. A distinct staining pattern for SC35 was observed when chromosomes were aligned at the equator of the cell. At this stage of the cell cycle, SC35 immunoreactivity decreased and diffuse staining, which does not colocalize with tau protein, is increased at this stage (Fig. 5 C, arrow). During separation of the sister chromatids to the poles, SC35 immunostaining decreases to a faint diffuse staining (Fig. 5D, green channel) in the daughter cells. At telophase, there were abundant speckles immunoreactive with SC35 (Fig. 5E). Associated with the newly formed nuclei, dense dots immunoreactive with SC35 colocalized with pT231 immunoreactivity (Fig. 5E, arrows). At this stage, however, the cytoplasmic reactivity to pT231 decreased.

Double immunostaining with SC35 and pT231 for SH-SY5Y cells treated with staurosporine

SH-SY5Y cells exposed to staurosporine favor the development of cytoplasmic extensions compared to untreated cultures and greater expression of tau protein (red channel) and SC35 (green channel) (Fig. 6A, B). In the cytoplasm, these markers were not colocalized. The anti-SC35 antibody showed perinuclear fibers in the direction of the prolongations.

Nuclear speckles, co-labeled with both SC35 and pT231, were observed in the nucleus. Additionally, diffuse granular staining with pT231, which did not colocalize with SC35, was observed in the terminals of the extensions, where there was a concentration of SC35 protein (Fig. 6B, arrowheads).

\section{Expression of nuclear tau protein in brains of $A D$} patients

The expression of phosphorylated N-terminal, conformational and truncated tau protein epitopes in NFTs and pre-NFTs was examined in brains from AD patients. Pre-NFTs are the first steps in the aggregation of tau protein in the neuronal soma. The pre-NFT was characterized by diffuse granular cytoplasmic staining revealed by pT231 (Fig. 7A, arrow) and TG3 (Fig. 7B), and a perinuclear staining with both antibodies was observed (Fig 7A, B). In the double immunostaining with the mAbs pSer404 and Alz50, labeling of an intracellular NFT with pS404 was observed (Fig. $7 \mathrm{C}$, arrowheads) in addition to staining within the nucleus (Fig. $7 \mathrm{C}, \mathrm{D}$, arrows) and, in the vicinity, dystrophic neurites immunoreactive to with Pronase and formic acid favored labelling by Alz50 in the nucleus (Fig. 7E, arrows) and an NFT reactive with $\mathrm{mAb} 423$ was observed nearby. Immunoelectron microscopy was used to establish Alz50 reactivity associated with nuclear heterochromatin (Fig. 7F, arrows). Alz50 were observed. Pre-treatment of the tissues 

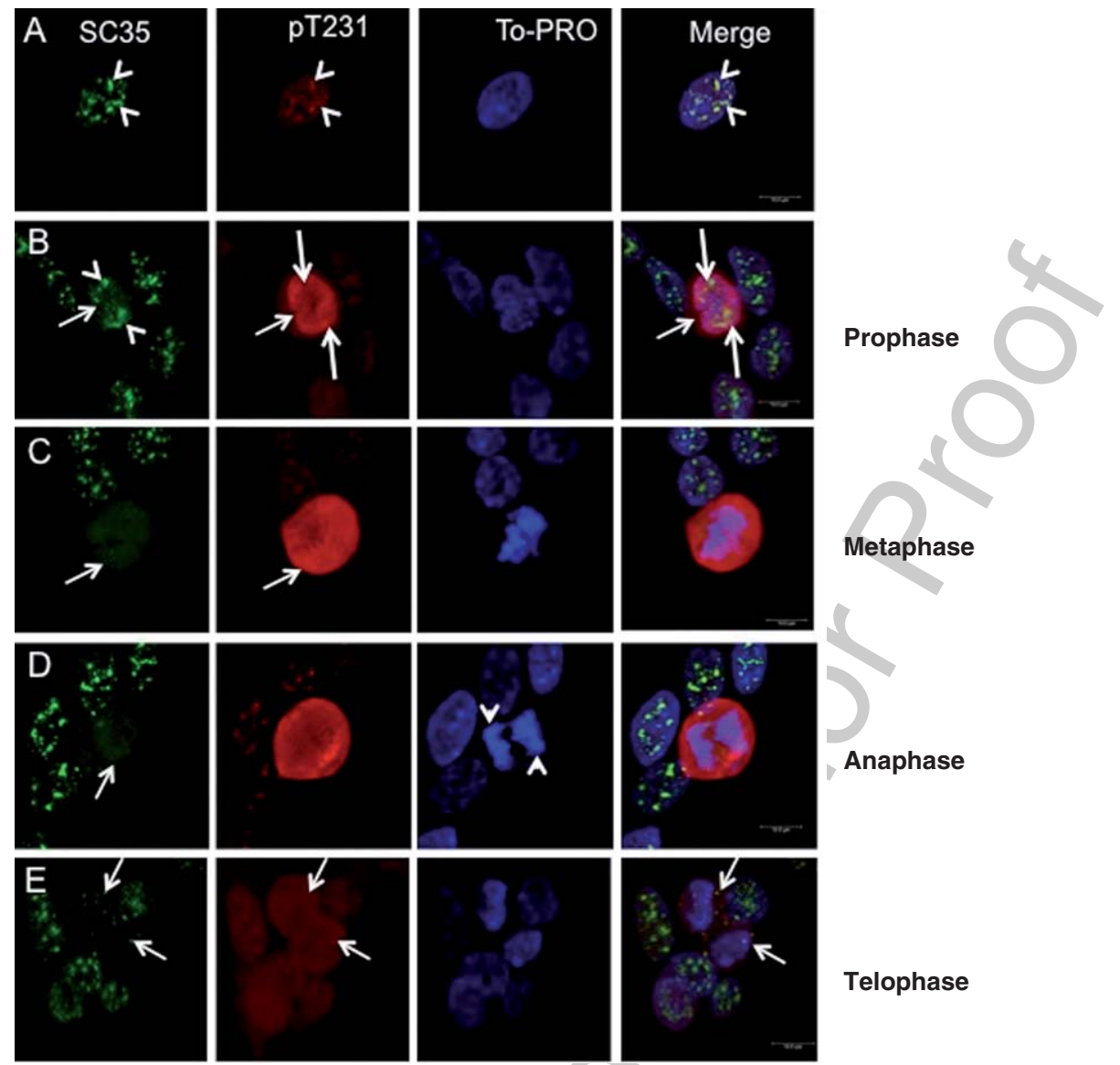

Anaphase
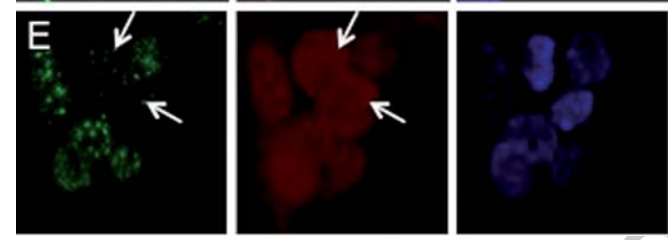

Telophase

Fig. 5. Double immunostaining with antibodies raised against the SC35 protein (green channel) and pT231 (red channel). In quiescent cells, SC35 immunoreactivity colocalized with dense granules positive for pT231. During cell cycle, SC35 immunoreactivity decreases markedly (B-E arrows, green channel), whereas pT231 immunoreactivity is increased during prophase and anaphase (B-E). During telophase, SC35 immunoreactivity is observed as dense spots, some of which colocalize with pT231 (arrows).

\section{DISCUSSION}

Phosphorylated tau protein in the nucleus of SH-SY5Y cells

Expression of tau protein is found in both neurons and non-neuronal cells [11]. In neurons, tau protein is located in the axon and dendritic terminals, where it serves to stabilize microtubules and assist in the transport of vesicles and organelles along the axon [37]. Under pathological conditions, tau protein acquires the ability to self-aggregate in paired helical filaments in $\mathrm{AD}$ and other dementias called tauopathies [38-43]. Visualization of the tau protein by routine immunohistochemistry and immunofluorescence in the axon of neurons under normal conditions is complicated. Similarly, its presence and function within the nucleus has been controversial. The observation of proteins within the nucleus depends on the method of fixation and permeabilization. Several studies have demonstrated the presence of nuclear tau protein; the variability of results may, in part, be due to the experimental system [44].

Our immunohistochemical study of tau protein in undifferentiated neuroblastoma cells (SH-SY5Y) reveals the expression of phosphorylated tau protein in dense speckles within the nucleus, consistent with previous studies $[16,45,46]$, and the presence of diffuse granular staining in the cytoplasm. Previous studies in neuroblastoma cells described the presence of non-phosphorylated tau protein recognized by the Tau- 1 antibody in the nucleolus. During cell cycle, Tau-1 immunoreactivity exhibits granular staining associated with chromosomes, suggesting that tau protein might have some normal physiological functions not necessarily associated with microtubules 

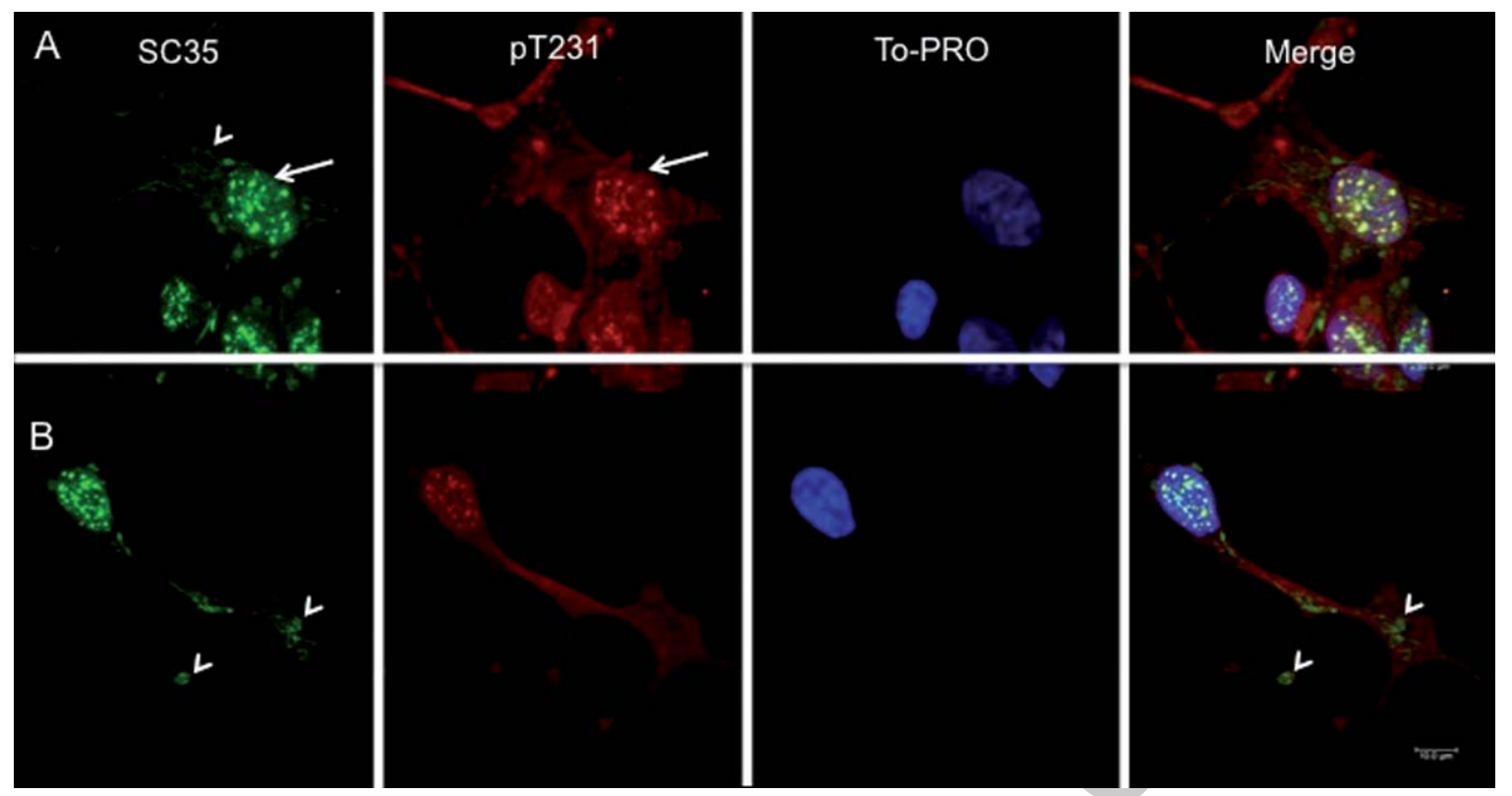

Fig. 6. Expression of SC35 and pT231 in undifferentiated staurosporine-treated SH-SY5Y cells. A) SC35 immunoreactivity is strong as dense spots within the nucleus, which colocalize with pT231 staining. SC35-immunoreactive staining was observed in the cytoplasm, which is independent of the staining to pT231 in the cytoplasm. B) In the cytoplasmic terminals, an increase in both pT231 tau and SC35 (arrowheads) signals is observed in cultures treated with staurosporine. In contrast, these markers do not colocalize in the cytoplasm (merged image, arrowhead).

$[16,47,48]$. It has been suggested that the role of tau depends on the functional status and development of the cell, which hints that tau protein may exert different functions. In resting MDCK and mesenchymal cells in resting, we could have recently observed evidence the of tau protein in dense specks within the nucleus. When the cells they enter the cell cycle, the expression of tau is increased similar to that observed in SHSY-5Y cells. This raises the following important question is important as to whether: the presence of the native nuclear tau protein in some certain cellular models could can modify its function when it is over overexpressed.

Other markers mainly reveal cytoplasmic tau, suggesting that tau protein can be found in different conformations and that different antibodies may not have access to particular epitopes [44]. In this study, and it important to emphasize, cells were fixed with $4 \%$ paraformaldehyde and permeabilized for 10 min with Triton X-100. Under these conditions, in SH-SY5Y cells, we observed expression of phosphorylated tau in nuclear speckles (pT231). These observations are in contrast to other studies, in which phosphorylated tau protein was not detected in the nucleus $[16,45]$. We suggest that tau protein can be found in both phosphorylated and dephosphory- lated forms in the nucleus. The localization may vary depending on the type of cell and in its intranuclear location. However, the roles that phosphorylated and non-phosphorylated tau protein play in the nucleus are not yet understood. A previous study showed the expression of recombinant tau protein in $\mathrm{CHO}$ cells during mitosis, the phosphorylated tau protein was observed in the cell nucleus expressed; tau was associated with the mitotic spindle [49]. This is in contrast with our observations for pT231, TG-3, and AD2 in SH-SY5Y cells, immunoreactivity of tau antibodies did not colocalize with the microtubular mitotic spindle. pT231 and TG-3 immunoreactivity is increased throughout the cytoplasm during metaphase. Phosphorylation at Thr-231 was observed throughout the cytoplasm of the cell, encompassing the entire mitotic spindle and chromosomes found at the equator of cells possibly organizing and maintaining the integrity of the chromosomes. In an immunohistochemical study of tau expression in the mouse testis, immunoreactivity with antibodies directed against phosphorylated tau protein was observed during meiosis, where the AT270 epitope (pT181) was expressed abundantly in the seminiferous tubules [50]. In past studies, pT231 was not observed, suggesting that tau protein plays a role 

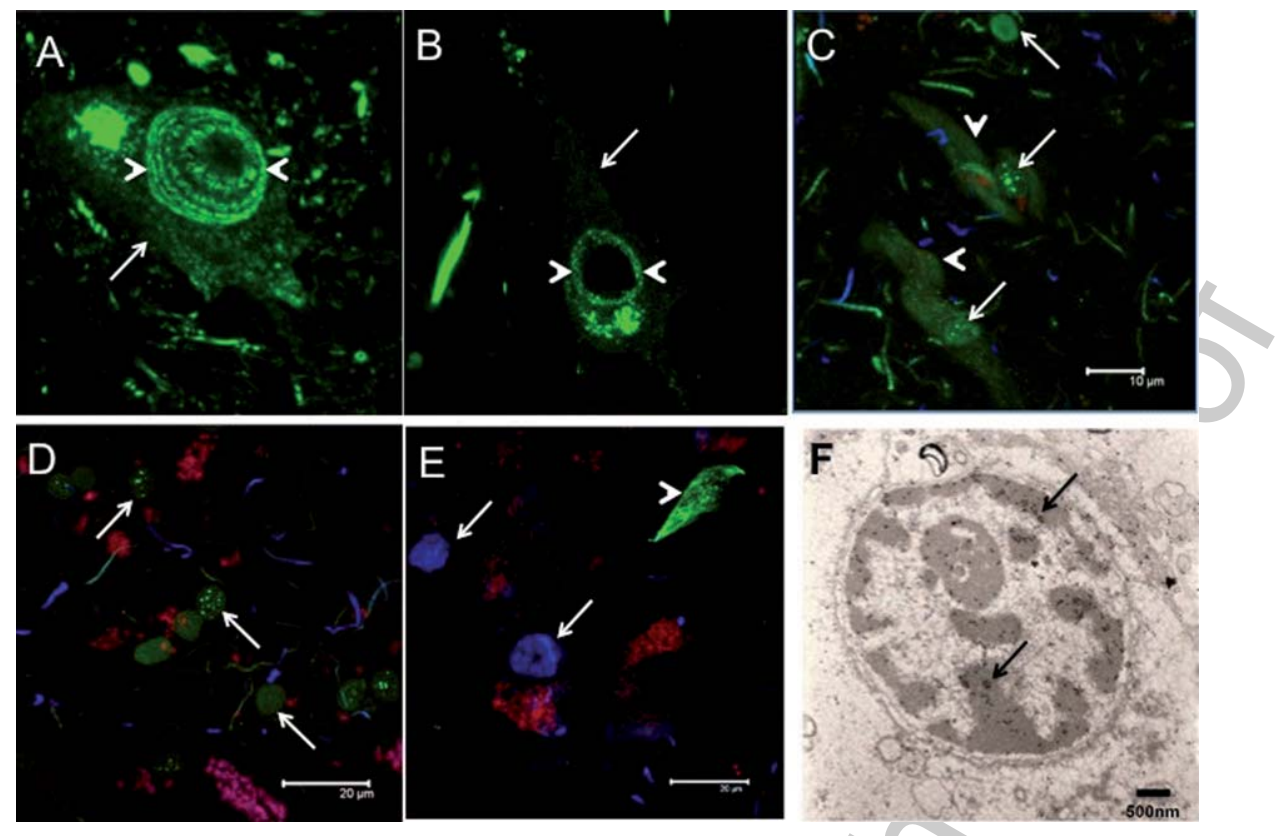

Fig. 7. Expression of tau protein in AD brain tissue. A, B) A pre-NFT immunoreactive to pT231, shows cytoplasmic granular staining (arrows) and an abundant staining in the perinuclear cells (arrowheads). C, D) Double labeling with the antibodies pS404 (green channel) and Alz50 (blue channel). C) Neurofibrillary tangle is reactive to pAb pS404 (arrowheads), and this antibody also shows immunoreactivity in the cell nucleus (arrows). At the periphery, dystrophic neurites are positive for both markers. D) pAb pS404 immunoreactivity is shown in nuclei (arrows), with Alz50 immunoreactivity in the peripheral dystrophic neurite. E) Double immunostaining with mAb 423 (green channel, arrowhead) and Alz50 (blue channel, arrows), following treatment with Pronase and formic acid, revealed abundant immunoreactivity for Alz50 in the nucleus of the neuronal cells (blue channel). Autofluorescent lipofuscin granules are also observed in the red channel. F) Immunoelectron microscopic staining with Alz50 shows the presence of abundant gold particles associated with nuclear heterochromatin (arrows).

in spermatogenesis. The variation on the expression of the epitopes of the tau protein observed can be both cell and tissue dependent [51]. The TG-3 antibody immunoreactivity evidences a conformational change dependent on phosphorylation (in the amino acids Thr231 and Ser235) [23]. In SHSY5Y cells, TG-3 immunoreactivity was seen only in cells that were undergoing cell division. The distribution pattern of the TG-3 immunoreactivity was diffuse and granular, but stronger immunoreactivity was observed in the vicinity of the chromosomes. This suggests that the phosphorylation of tau protein at Thr231, associated with the conformational change, may be facilitated in maintaining the individuality of the chromosomes at the time of cell division. Furthermore, no colocalization was observed with tubulin in the mitotic spindle. Stronger immunoreactivity of TG-3 was observed in the metaphase when the chromosomes are condensed at the equator. This is consistent with previous studies in which the presence of phosphoepitopes, such as TG-3, appear just prior to the prophase with maximal expression during metaphase [52]. In AD, the TG-3 epitope has been associated with early events of tau protein aggregation (pre-NFT) prior to the formation of paired helical filaments [53, 54]. Antibody AD2 (which requires phosphorylation of amino acids serine at positions 396 and serine 404) showed a granular staining in the cytoplasm of quiescent cells. The immunoreactivity detected with this antibody increases as does that of the pT231 and TG-3 antibodies in dividing cells. A specific feature of the AD2 antibody is that its immunoreactivity is increased between the mitotic spindles during the separation, at anaphase, of the sister chromatids toward the poles of the cell. Thus, tau might function in the movement and separation of the sister chromatids towards their corresponding centrosomes. Our study has revealed that three tau epitopes are involved in the cell cycle in SH-SY5Y cells: pT231, TG-3, and AD2. The appearance of reactivity to these antibodies at different stages of mitosis, suggest that multiple functions for tau may depend on both the nature of the epitopes exposed and on the stage of the cell cycle at which they are found. The phosphorylation of tau at Thr-231 favors a possible protection and coordination of chromosomes; TG-3 
possibly keep the individuality of the chromosomes and AD2 is involved in the movement and separation of the chromatids toward the poles.

Further functions for tau may be involved in the differentiation of neurons. Tau protein was preferentially expressed in cytoplasmic extensions although, for some cells, tau remained in the nucleus. These observations suggest that the translocation of tau from the nucleus to the cytoplasm during the transition from the undifferentiated to the differentiated state may be part of this cellular programming [17]. Previous studies have described the localization of phosphorylated tau protein in LA-N-5 cells, where tau protein was observed in both the cytoplasm and nucleus. Immunofluorescent staining showed that nuclear tau protein is preferentially located in the nucleolus; Greenwood JA et al. revealed that $16 \%$ of the total tau protein is located in the nucleus, since tau phosphorylation is observed in the cytoplasm prior to its translocation to the nucleus [45]. So far, no function has been associated with this form of nuclear tau. However, other investigators have proposed mechanisms for tau protecting DNA in heat-stressed neurons [55]. Our results showed that tau phosphorylated at Thr-231 was found in the cytoplasm when cells were exposed to staurosporine, an inducer of apoptosis. Previous studies have shown that overexpression of phospho-tau inhibits apoptosis $[46,56]$ and, in contrast, its dephosphorylated form potentiates apoptosis [57].

The study of tau protein has been based on its physiological processing involved in its association and stability of microtubules and its pathological modifications associated with neurodegenerative diseases. A better understanding of the location and function of tau protein within the nucleus is required. The presence of tau protein in the nucleus and in the nucleolus suggests that it could be involved in the protection of the genome. However, the nature of their translocation to the nucleus, conformation and interaction of tau protein with DNA and other nuclear proteins suggests that it could play multiple functions. Our results have shown that the expression of tau protein in intranuclear dots colocalized with immunoreactivity to an antibody raised against the SC 35 protein, a protein involved in the inclusion of the fourth repeated domain of tau. However, SC35 functions inside the nucleus and is reported as the only one of the SR proteins involved in RNA splicing that remains in the nucleus. Previous studies have co-precipitated the pre-mRNA with SC35, suggesting that SC35 acts on the exonic splicing enhancer for the inclusion of tau exon 10. It has been suggested that, in $\mathrm{AD}$, the deregulation of tau exon 10 through SC35 associated with other splice factors favors an uneven expression of the $3 \mathrm{R}$ and $4 \mathrm{R}$ tau isoforms that could initiate or potentiate tau pathology by triggering neurofibrillary degeneration [58]. This would be consistent with our findings in which apoptosis in the SH-SY5Y cells were induced with staurosporine. We observed a morphological change in the cells in which cytoplasmic extensions were formed and also observed that SC35 was found not only in the nucleus but also in the cytoplasm. In addition, it has been observed that staurosporine is involved in neurite outgrowth [59]. The SC35 analysis carried out in dividing neuroblastoma cells. It would be of interest to examine the expression of SC 35 and tau protein in differentiated cell and in primary neuronal cultures

Our findings suggest that the presence of a specific tau protein conformation, detected by AD2, is involved in the separation of sister chromatid in anaphase, and that other phospho-tau forms maintain the integrity of DNA in prophase (pT231) and chromosomes during cell division (TG-3). Further investigations may identify other subtle changes in functions for the protein in the nucleus.

\section{Nuclear tau in $A D$}

In spite of being an abundant tau protein in the brain, it is difficult to visualize tau in the axon and its visualization in the nucleus is even more complicated. The presence of tau in the nucleus has been associated with protection mechanisms against DNA damage. It is suggested that the tau protein could be protecting the DNA against the changes that happen in the neuronal soma due to the massive accumulation of this protein. In AD brain, phospho-tau protein is expressed in a diffuse granular form in the cytoplasm in the first stages of aggregation (preNFT). It is important to emphasize that this protein has been commonly observed in the perinuclear zone. The antibody (pS404) that recognizes tau phosphorylated at amino acid serine 404 was observed to label both NFTs and intranuclear staining. A series of dense specks were observed within the nucleus. Not all antibodies showed an affinity for intranuclear tau. This is possibly due to the fixation methods and/or proteins to which tau is associated within the nucleus. When the hippocampal sections were treated with Pronase and formic acid, abundant immunoreactivity was observed with the Alz50 antibody within the neuronal nucleus. These observations were corroborated 
by immuno-gold staining where tau-reactive particles were observed abundantly in the heterochromatin and in the nucleolus.

More evidence is needed to determine the possible protective effect of tau protein in $\mathrm{AD}$ as a consequence of its extensive accumulation in the neuronal soma; or instead, it is possible participation in an inflammatory process that favors the accumulation of extracellular deposits of amyloid beta peptide. More studies are needed to fully understand the activity or participation of tau protein in the nucleus.

\section{ACKNOWLEDGMENTS}

Authors want to express their gratitude to Dr. P. Davies (Albert Einstein College of Medicine, Bronx, NY, USA); Lester I. Binder ${ }^{\dagger}$ (North Western, Chicago, IL, USA) for the generous gift of mAbs (TG-3, Alz-50) and (Tau-1, Tau-5, Tau-7), respectively; Tec. Amparo Viramontes Pintos for the handling of the brain tissue; M. en C. Samadhi Moreno-Campuzano for her technical assistance; $\mathrm{M}$ en C.J. Iván Gálvan for his support in confocal microscopy, and the confocal microscopy unit of Laboratorio Nacional de Servicios Experimentales (LaNSE), CINVESTAV. We also want to express our gratitude to the Mexican families who donated brains of loved ones affected with Alzheimer's disease, and made our research possible. This work is dedicated to the memory of Professor Dr. José Raúl Mena López ${ }^{\dagger}$. This work was financially supported by CONACyT grants, No. 142293 (to R.M.), 266492 (I.V-F), 239516 (J.S) and the Mancera-Reséndiz family.

Authors' disclosures available online (https:// www.j-alz.com/manuscript-disclosures/19-0155r2).

\section{REFERENCES}

[1] Tilney LG, Gibbins JR (1969) Microtubules in the formation and development of the primary mesenchyme in Arbacia punctulata. II. An experimental analysis of their role in development and maintenance of cell shape. J Cell Biol 41, 227-250.

[2] Stephens RE, Edds KT (1976) Microtubules: structure, chemistry, and function. Physiol Rev 56, 709-777.

[3] Luduena RF, Shooter EM, Wilson L (1977) Structure of the tubulin dimer. J Biol Chem 252, 7006-7014.

[4] Mandelkow E, Mandelkow EM (1995) Microtubules and microtubule-associated proteins. Curr Opin Cell Biol 7, 7281.

[5] Buee L, Bussiere T, Buee-Scherrer V, Delacourte A, Hof PR (2000) Tau protein isoforms, phosphorylation and role in neurodegenerative disorders. Brain Res Brain Res Rev 33, $95-130$.

[6] McLaughlin L, Zemlan FP, Dean GE (1997) Identification of microtubule-associated protein tau isoforms in Alzheimer's paired helical filaments. Brain Res Bull 43, 501-508.

[7] Ruben GC, Novak M, Edwards PC, Iqbal K (2005) Alzheimer paired helical filaments (PHFs) studied by highresolution TEM: what can vertical $\mathrm{Pt}-\mathrm{C}$ replication tell us about the organization of the pronase-digested PHF core? Microsc Res Tech 67, 196-209.

[8] Ruben GC, Wang JZ, Iqbal K, Grundke-Iqbal I (2005) Paired helical filaments (PHFs) are a family of single filament structures with a common helical turn period: negatively stained PHF imaged by TEM and measured before and after sonication, deglycosylation, and dephosphorylation. Microsc Res Tech 67, 175-195.

[9] Pooler AM, Hanger DP (2010) Functional implications of the association of tau with the plasma membrane. Biochem Soc Trans 38, 1012-1015.

[10] Cross DC, Munoz JP, Hernandez P, Maccioni RB (2000) Nuclear and cytoplasmic tau proteins from human nonneuronal cells share common structural and functional features with brain tau. J Cell Biochem 78, 305-317.

[11] Lee G, Rook SL (1992) Expression of tau protein in nonneuronal cells: microtubule binding and stabilization. J Cell Sci 102 (Pt 2), 227-237.

[12] Maj M, Hoermann G, Rasul S, Base W, Wagner L, Attems J (2016) The microtubule-associated protein tau and its relevance for pancreatic beta cells. J Diabetes Res $\mathbf{2 0 1 6}$, 1964634.

[13] Thurston VC, Zinkowski RP, Binder LI (1996) Tau as a nucleolar protein in human nonneural cells in vitro and in vivo. Chromosoma 105, 20-30.

[14] Tanaka T, Zhong J, Iqbal K, Trenkner E, Grundke-Iqbal I (1998) The regulation of phosphorylation of tau in SY5Y neuroblastoma cells: the role of protein phosphatases. FEBS Lett 426, 248-254.

[15] Tanaka T, Iqbal K, Trenkner E, Liu DJ, Grundke-Iqbal I (1995) Abnormally phosphorylated tau in SY5Y human neuroblastoma cells. FEBS Lett 360, 5-9.

[16] Loomis PA, Howard TH, Castleberry RP, Binder LI (1990) Identification of nuclear tau isoforms in human neuroblastoma cells. Proc Natl Acad Sci U S A 87, 8422-8426.

[17] Uberti D, Rizzini C, Spano PF, Memo M (1997) Characterization of tau proteins in human neuroblastoma SH-SY5Y cell line. Neurosci Lett 235, 149-153.

[18] Spector DL, Lamond AI (2011) Nuclear speckles. Cold Spring Harb Perspect Biol 3, a000646.

[19] McKhann G, Drachman D, Folstein M, Katzman R, Price D, Stadlan EM (1984) Clinical diagnosis of Alzheimer's disease: report of the NINCDS-ADRDA Work Group under the auspices of Department of Health and Human Services Task Force on Alzheimer's Disease. Neurology 34, 939-944.

[20] Guillemin I, Becker M, Ociepka K, Friauf E, Nothwang HG (2005) A subcellular prefractionation protocol for minute amounts of mammalian cell cultures and tissue. Proteomics 5, 35-45.

[21] Carmel G, Mager EM, Binder LI, Kuret J (1996) The structural basis of monoclonal antibody Alz50's selectivity for Alzheimer's disease pathology. J Biol Chem 271, 3278932795.

[22] Jicha GA, Bowser R, Kazam IG, Davies P (1997) Alz-50 and MC-1, a new monoclonal antibody raised to paired helical filaments, recognize conformational epitopes on recombinant tau. J Neurosci Res 48, 128-132. 
[23] Jicha GA, Lane E, Vincent I, Otvos L, Jr., Hoffmann R, Davies P (1997) A conformation- and phosphorylationdependent antibody recognizing the paired helical filaments of Alzheimer's disease. J Neurochem 69, 2087-2095.

[24] Bihaqi SW, Zawia NH (2013) Enhanced taupathy and ADlike pathology in aged primate brains decades after infantile exposure to lead (Pb). Neurotoxicology 39, 95-101.

[25] Zheng-Fischhofer Q, Biernat J, Mandelkow EM, Illenberger S, Godemann R, Mandelkow E (1998) Sequential phosphorylation of Tau by glycogen synthase kinase-3beta and protein kinase A at Thr212 and Ser214 generates the Alzheimer-specific epitope of antibody AT100 and requires a paired-helical-filament-like conformation. Eur J Biochem 252, 542-552.

[26] Buee-Scherrer V, Condamines O, Mourton-Gilles C, Jakes R, Goedert M, Pau B, Delacourte A (1996) AD2, a phosphorylation-dependent monoclonal antibody directed against tau proteins found in Alzheimer's disease. Brain Res Mol Brain Res 39, 79-88.

[27] Song L, Lu SX, Ouyang X, Melchor J, Lee J, Terracina G, Wang X, Hyde L, Hess JF, Parker EM, Zhang L (2015) Analysis of tau post-translational modifications in rTg4510 mice, a model of tau pathology. Mol Neurodegener 10, 14.

[28] Sato S, Sakurai T, Ogasawara J, Shirato K, Ishibashi Y, Ohishi S, Imaizumi K, Haga S, Hitomi Y, Izawa T, Ohira Y, Ohno H, Kizaki T (2014) Direct and indirect suppression of interleukin- 6 gene expression in murine macrophages by nuclear orphan receptor REV-ERBalpha. ScientificWorldJournal 2014, 685854.

[29] LoPresti P, Szuchet S, Papasozomenos SC, Zinkowski RP, Binder LI (1995) Functional implications for the microtubule-associated protein tau: localization in oligodendrocytes. Proc Natl Acad Sci U S A 92, 10369-10373.

[30] Binder LI, Frankfurter A, Rebhun LI (1985) The distribution of tau in the mammalian central nervous system. J Cell Biol 101, 1371-1378

[31] Horowitz PM, LaPointe N, Guillozet-Bongaarts AL, Berry RW, Binder LI (2006) N-terminal fragments of tau inhibit full-length tau polymerization in vitro. Biochemistry $\mathbf{4 5}$, 12859-12866.

[32] Merrick SE, Demoise DC, Lee VM (1996) Site-specific dephosphorylation of tau protein at Ser202/Thr205 in response to microtubule depolymerization in cultured human neurons involves protein phosphatase 2A. J Biol Chem 271, 5589-5594.

[33] Wischik CM, Edwards PC, Lai RY, Roth M, Harrington CR (1996) Selective inhibition of Alzheimer disease-like tau aggregation by phenothiazines. Proc Natl Acad Sci U S A 93, 11213-11218.

[34] Fu XD, Maniatis T (1990) Factor required for mammalian spliceosome assembly is localized to discrete regions in the nucleus. Nature 343, 437-441.

[35] Ryan TE, Schmidt CA, Green TD, Spangenburg EE, Neufer PD, McClung JM (2016) Targeted expression of catalase to mitochondria protects against ischemic myopathy in highfat diet-fed mice. Diabetes 65, 2553-2568.

[36] Mena R, Edwards P, Perez-Olvera O, Wischik CM (1995) Monitoring pathological assembly of tau and beta-amyloid proteins in Alzheimer's disease. Acta Neuropathol 89, 5056.

[37] Johnson GV, Stoothoff WH (2004) Tau phosphorylation in neuronal cell function and dysfunction. J Cell Sci 117, 57215729.

[38] Abner EL, Kryscio RJ, Schmitt FA, Santacruz KS, Jicha GA, Lin Y, Neltner JM, Smith CD, Van Eldik LJ, Nelson
PT (2011) "End-stage" neurofibrillary tangle pathology in preclinical Alzheimer's disease: fact or fiction? JAlzheimers Dis 25, 445-453.

[39] Defossez A, Beauvillain JC, Delacourte A, Mazzuca M (1988) Alzheimer's disease: a new evidence for common epitopes between microtubule associated protein Tau and paired helical filaments (PHF): demonstration at the electron microscope level by a double immunogold labelling. Virchows Arch A Pathol Anat Histopathol 413, 141-145.

[40] Gertz HJ, Xuereb JH, Huppert FA, Brayne C, Kruger H, McGee MA, Paykel ES, Harrington CR, MukaetovaLadinska EB, O'Connor DW, Wischik CM (1996) The relationship between clinical dementia and neuropathological staging (Braak) in a very elderly community sample. Eur Arch Psychiatry Clin Neurosci 246, 132-136.

[41] Kolarova M, Garcia-Sierra F, Bartos A, Ricny J, Ripova D (2012) Structure and pathology of tau protein in Alzheimer disease. Int J Alzheimers Dis 2012, 731526.

[42] Spillantini MG, Goedert M, Jakes R, Klug A (1990) Topographical relationship between beta-amyloid and tau protein epitopes in tangle-bearing cells in Alzheimer disease. Proc Natl Acad Sci U S A 87, 3952-3956.

[43] Wang Y, Mandelkow E (2016) Tau in physiology and pathology. Nat Rev Neurosci 17, 5-21.

[44] Lu J, Li T, He R, Bartlett PF, Gotz J (2014) Visualizing the microtubule-associated protein tau in the nucleus. Sci China Life Sci 57, 422-431.

[45] Greenwood JA, Johnson GV (1995) Localization and in situ phosphorylation state of nuclear tau. Exp Cell Res 220, 332337.

[46] Mookherjee P, Johnson GV (2001) Tau phosphorylation during apoptosis of human SH-SY5Y neuroblastoma cells. Brain Res 921, 31-43.

[47] Bukar Maina M, Al-Hilaly YK, Serpell LC (2016) Nuclear tau and its potential role in Alzheimer's disease. Biomolecules $6,9$.

[48] Uberti D, Rizzini C, Galli P, Pizzi M, Grilli M, Lesage A, Spano P, Memo M (1997) Priming of cultured neurons with sabeluzole results in long-lasting inhibition of neurotoxininduced tau expression and cell death. Synapse 26, 95-103.

[49] Preuss U, Doring F, Illenberger S, Mandelkow EM (1995) Cell cycle-dependent phosphorylation and microtubule binding of tau protein stably transfected into Chinese hamster ovary cells. Mol Biol Cell 6, 1397-1410.

[50] Sigala J, Jumeau F, Caillet-Boudin ML, Sergeant N, Ballot C, Rigot JM, Marcelli F, Tardivel M, Buee L, Mitchell V (2014) Immunodetection of Tau microtubule-associated protein in human sperm and testis. Asian J Androl 16, $927-$ 928.

[51] Inoue H, Hiradate Y, Shirakata Y, Kanai K, Kosaka K, Gotoh A, Fukuda Y, Nakai Y, Uchida T, Sato E, Tanemura K (2014) Site-specific phosphorylation of Tau protein is associated with deacetylation of microtubules in mouse spermatogenic cells during meiosis. FEBS Lett 588, 2003-2008

[52] Vincent I, Rosado M, Davies P (1996) Mitotic mechanisms in Alzheimer's disease? J Cell Biol 132, 413-425.

[53] Luna-Munoz J, Chavez-Macias L, Garcia-Sierra F, Mena R (2007) Earliest stages of tau conformational changes are related to the appearance of a sequence of specific phosphodependent tau epitopes in Alzheimer's disease. J Alzheimers Dis 12, 365-375.

[54] Luna-Munoz J, Garcia-Sierra F, Falcon V, Menendez I, Chavez-Macias L, Mena R (2005) Regional conformational change involving phosphorylation of tau protein at the Thr231, precedes the structural change detected by 
Alz-50 antibody in Alzheimer's disease. J Alzheimers Dis 8 , 29-41.

[55] Sultan A, Nesslany F, Violet M, Begard S, Loyens A, Talahari S, Mansuroglu Z, Marzin D, Sergeant N, Humez S, Colin M, Bonnefoy E, Buee L, Galas MC (2011) Nuclear tau, a key player in neuronal DNA protection. $J$ Biol Chem 286, 4566-4575.

[56] Wang HH, Li HL, Liu R, Zhang Y, Liao K, Wang Q, Wang JZ, Liu SJ (2010) Tau overexpression inhibits cell apoptosis with the mechanisms involving multiple viability-related factors. J Alzheimers Dis 21, 167-179.
[57] Davis PK, Johnson GV (1999) Energy metabolism and protein phosphorylation during apoptosis: a phosphorylation study of tau and high-molecular-weight tau in differentiated PC12 cells. Biochem J 340 (Pt 1), 51-58.

[58] Montejo de Garcini E, Corrochano L, Wischik CM, Diaz Nido J, Correas I, Avila J (1992) Differentiation of neuroblastoma cells correlates with an altered splicing pattern of tau RNA. FEBS Lett 299, 10-14.

[59] Zhaleh H, Azadbakht M, Pour AB (2014) Phosphoinositid signal pathway mediate neurite outgrowth in PC12 cells by staurosporine. Bratisl Lek Listy 115, 203-208. 